\title{
SNAPSHOT Trouble in paradise
}

\section{Bali's first confirmed} human victim of $\mathrm{H} 5 \mathrm{~N} 1$ bird flu, Ni Luh Putu Sri Windiani, is transported in a sealed coffin from Sanglah hospital in Denpasar. The 29-year-old woman from Tukadaye village in Jembrana died on 12 August. Her death brings Indonesia's total number of fatalities from bird flu to 82, and hits its main tourist destination while it is still reeling from terrorist incidents.

Windiani's five-year-old daughter Dian developed a fever after playing with chickens, and died on 3 August. Tests have not been carried out on Dian, who has already been buried. Indonesia's bird flu commission is waiting for test results from a 2-yearold girl living nearby who is also suspected of having bird flu. In recent weeks many chickens had become sick and died suddenly in Tukadaye, and instead of burning the carcasses, the villagers fed

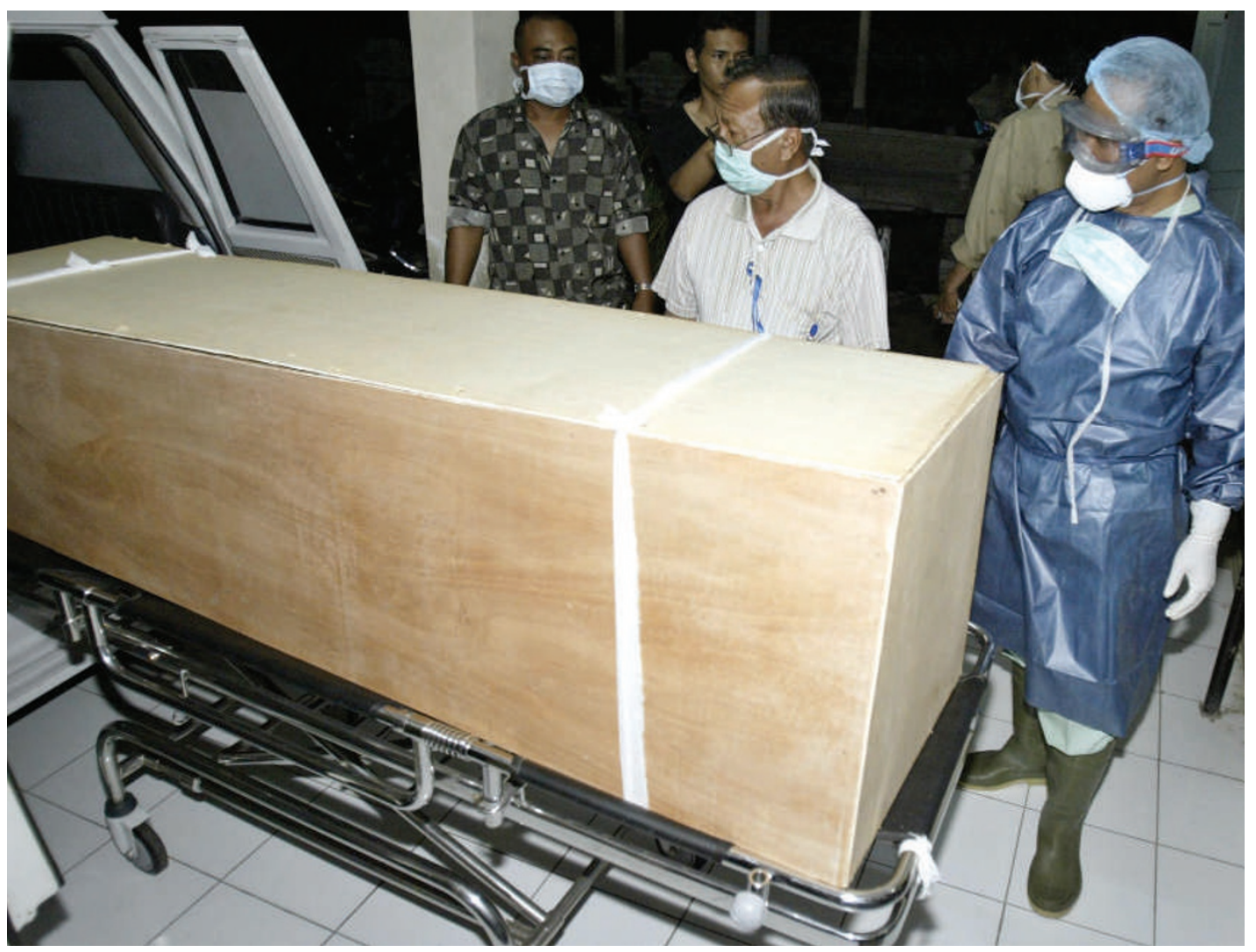

them to pigs or buried them, officials say. This is of special concern, because scientists think that pigs infected with both avian flu viruses and human flu viruses are a likely source of the pandemic versions that periodically kill millions of people across the globe.

"The situation is bad," Chairul Nidom, a virologist at Airlangga University in Surabaya, Java, told Nature. "We don't know yet how the infections happened. Maybe they passed though another animal."

A law preventing $\mathrm{H} 5 \mathrm{~N} 1$-infected poultry entering Bali was revoked in July by the Home Ministry.

David Cyranoski

\section{Transparency urged over research payments}

Charles Grassley, the Republican senator for Iowa, has said that he will introduce legislation to set up a national public registry of payments made to doctors by pharmaceutical companies.

Four states and the District of Columbia already have laws requiring such disclosures. But, Grassley says, such laws should be rolled out nationwide. "For the sake of transparency and accountability, shouldn't the American public know who their doctor [sic] is taking money from?" Grassley asked in a speech on the Senate floor on 2 August.

Grassley is not the first legislator to propose a registry, and his office did not provide details of his plan. Whatever the plan entails, it is likely to meet resistance from the American Medical Association and the Pharmaceutical Research and Manufacturers of America.

Public unease with lucrative arrangements between researchers and industry has grown in recent years, increasing demand for more information about these ties. Questions about drug safety have highlighted the issue of whether industry-sponsored research by academic scientists is trustworthy. And a 2003 scandal over conflicts of interest at the National Institutes of Health, Bethesda, Maryland, embarrassed the agency and led to predictions that the practice would spill over to universities (see Nature 431, 725; 2004).

Now, this seems to be occurring. In his speech, Grassley acknowledged that universities often require their researchers to disclose payments from outside sources, but said there are flaws with this system. For instance, it relies on the researcher to make accurate disclosures, which are not generally released to the public. Now, Grassley is asking universities for more information about how well the process works.
Observers say a national registry should improve on the shortcomings of existing state registries. "The states deserve credit for being a source of innovation on this issue, but not one of them has produced complete or readily accessible disclosure," says Peter Lurie of the watchdog group Public Citizen, in Washington DC.

An analysis of drug payment disclosures in Vermont and Minnesota has found serious loopholes and a lack of enforcement (J. S. Ross et al. J. Am. Med. Assoc. 297, 1216-1223; $2007)$. For instance, $61 \%$ of payments to Vermont physicians were not made public because the state's law allows companies to designate the information as a "trade secret". And only one-quarter of drug companies in Minnesota reported their payments, which did nothing to ensure compliance with the law, Lurie says. Erika Check 